\title{
Território de plantar, collher e adoecer? Produção agrícola, agrotóxicos e adoecimento em Goiás, Brasil (2000 a 2013)
}

\author{
Land for planting, harvesting and sickness? Agricultural production, \\ pesticides and disease in Goiás, Brazil (2000 to 2013)
}

\author{
Giovana Galvão Tavares ${ }^{1}$ \\ Antonio Cezar Leal ${ }^{2}$ \\ Francisco Itami Campos ${ }^{3}$ \\ Dulcinea Maria Barbosa Campos 4 \\ Luan Herinque de Jesus ${ }^{5}$ \\ Odaiza Ferreira de Sousa ${ }^{6}$
}

\section{Palavras-chave: \\ Bioma Cerrado \\ Intoxicação \\ Microrregião de Ceres}

\begin{abstract}
Resumo
Este artigo tem por objetivo discutir a expansão do agronegócio no estado de Goiás, Brasil, o uso de agrotóxicos e o adoecimento da população nos anos 2000 a 2013, com ênfase em cinco municípios localizados na Microrregião de Ceres (Goianésia, Itapaci, Uruana, Rialma e Barro Alto). O procedimento metodológico consistiu em pesquisa bibliográfica, análise exploratória de dados e análise descritiva e estatística não paramétrica. Os resultados demonstram que nos anos 2000 a 2013 o estado de Goiás e os municípios investigados tiveram crescimento da área urbana; redução do bioma Cerrado e aumento da produtividade agrícola da cana-de-açúcar, milho e soja, acompanhados, conforme dados registrados em sistemas de informação em saúde, do aumento de casos de intoxicação, tentativas de suicídios com uso de agrotóxico, neoplasias e malformações congênitas.
\end{abstract}

\section{Keywords:}

Cerrado biome

Poisoning

Microrregion of Ceres

\begin{abstract}
This article discusses the expansion of agribusiness in the state of Goiás, Brazil, the use of toxic agrochemicals or pesticides, and the resulting ailments contracted by the local population between 2000 and 2013, with emphasis on five municipalities located in the microregion of Ceres (Goianesia, Itapaci, Uruana, Rialma and Barro Alto). The approach employed in this study consisted of bibliographical research, an exploratory analysis of the data, and a non-parametric descriptive and statistical analysis. The findings reveal marked urban expansion in the aforementioned municipalities in the state of Goiás from 2000 to 2013, a
\end{abstract}

\footnotetext{
${ }^{1}$ Centro Universitário de Anápolis, Goiás, Brasil. . E-mail: gio.tavares@gmail.com

${ }^{2}$ Universidade Estadual Paulista-Presidente Prudente, São Paulo, Brasil. E-mail: cezar.leal@unesp.br

${ }^{3}$ Centro Universitário de Anápolis, Goiás, Brasil. E-mail: itami@gmail.com

${ }^{4}$ Centro Universitário de Anápolis, Goiás, Brasil. E-mail dulcinea.bcampos@gmail.com

5 Centro Universitário de Anápolis, Goiás, Brasil. E-mail: luan.academico.bio@gmail.com

${ }^{6}$ Centro Universitário de Anápolis, Goiás, Brasil. E-mail: odaiza19@hotmail.com
} 
shrinking Cerrado biome, and augmented agricultural productivity of sugarcane, corn and soy, accompanied by an increase in the number of poisoning victims, suicide attempts using pesticides, neoplasms and congenital malformations, according to data recorded in public health information systems.

\section{INTRODUÇÃO}

A cadeia produtiva do agronegócio brasileiro tornou-se dependente do consumo intensivo de agroquímicos que provocam contaminações no ambiente e perda de saúde dos seres vivos, promovendo o adoecimento dos seres humanos, extinção de espécies animais e vegetais, e, ainda, aumentam pragas resistentes aos produtos químicos (ABREU; ALONZO, 2016; CARNEIRO et al., 2015; JOBIM, 2010; PORTO; SOARES, 2012; SILVA, 2005; STOPPELLI, 2005).

Conforme Albuquerque et al. (2015), o agronegócio gerou em 1991, 8,8 bilhões de dólares para a balança comercial nacional e em $2012,79,4$ bilhões de dólares. No período de 2000 a 2008, o mercado mundial do agrotóxico cresceu $45,4 \%$ e no Brasil 176,0\%. Desde então, o país está entre os 10 países que mais consomem agrotóxicos no mundo e, consequentemente, tem aumentado os riscos à saúde da população exposta aos agroquímicos.

O agronegócio é uma das principais atividades de desenvolvimento econômico em Goiás. Sua territorialização no estado deu-se de forma heterogênica e foi organizado, dentre outros fatores, considerando-se a topografia e a abundância de recursos hídricos (MATOS, 2013). Atualmente esse modelo de produção agrícola tem se expandido no estado, especialmente os cultivos de soja, milho e cana-de-açúcar.

Segundo o Instituto Mauro Borges (IMB), entre 2000 a 2013, ocorreu aumento da produtividade das três culturas mencionadas, evidenciando a intensificação do uso de insumos (IMB, 2018). Dentre os insunos, conforme Relatório Vigilância em Saúde de Populações Expostas a Agrotóxicos no Estado de Goiás (BRASIL, 2016), estão os agrotóxicos que contribuíram direta ou indiretamente para o aumento de adoecimento por intoxicações agudas ou crônicas.

Destarte, os malefícios provocados à saúde humana pelo uso de agrotóxicos tem sido alvo de pesquisas da comunidade científica nacional (ABREU; ALONZO, 2016; CORCINO, 2019; JOBIM, 2010; PORTO; SOARES, 2012; SILVA, 2005; STOPPELLI, 2005), internacional (ACQUAVELLA, 1998; ALAVANJA et al., 2003; 2004; DOULL; LEVINE, 1993; EATON, 2008;
LEVINE; DOULL, 1992), Instituições Nacionais (Fórum Estadual de Combate aos Impactos dos Agrotóxicos do Estado do Rio de Janeiro, Associação Brasileira de Saúde Coletiva, Conselho Nacional de Segurança Alimentar e Nutricional, Fundação Osvaldo Cruz e Instituto Nacional de Cancer José de Alencar Gomes da Silva) e Internacionais (International Agency for Research on Cancer; Human Rights Watch). Ressalta-se que entre as temáticas tratadas estão aquelas que correlacionam doenças crônicas e congênitas com o uso e consumo de agrotóxicos, especialmente em áreas em que ocorre a territorialização do agronegócio.

Neste contexto, este artigo tem por objetivo discutir a expansão do agronegócio no estado Goiás, o uso de agrotóxicos e adoecimento da população nos anos 2000 a 2013, com ênfase em cinco municípios localizados na Microrregião de Ceres, Goiás, a saber: Goianésia, Itapaci, Uruana, Rialma e Barro Alto.

Busca-se responder as seguintes indagações: No decorrer dos anos de 2000 a 2013 ocorreu aumento da produção agrícola da cana-de-açúcar, milho e soja, bem como o aumento do uso de agrotóxicos nos municípios pesquisados? No decorrer dos anos de 2000 a 2013 ocorreu aumento de casos de doenças como neoplasia, malformação congênita e intoxicação por agrotóxicos nos municípios pesquisados? A população residente nos municípios está exposta a que tipo de agrotóxico?

Para responder a tais indagações recorreu-se aos dados disponibilizados nos sistemas de informação: Sistema de Informação do Instituto Mauro Borges, Centro de Informação Toxicológica de Goiás (CIT - GO); Sistema Nacional de Informações Tóxico-Farmacológicas (SINITOX); Sistema de Informação em Saúde do Estado de Goiás; Sistema de Informação do Câncer (SISCAN), Sistema de Informação sobre Mortalidade (SIM), Sistema de Informação de Agravos de Notificação (SINAN); Ministério da Agricultura, Pecuária e Abastecimento (MAPA) e Agência Goiana de Defesa Agropecuária (AGRODEFESA).

O procedimento metodológico utilizado para esta pesquisa consistiu, também, da análise exploratória de dados, cuja finalidade foi examinar os dados previamente à aplicação de qualquer técnica estatística a fim de compreender 
e compilar, sempre que possível, os dados obtidos nos diferentes sistemas de informação e arquivos físicos e, posteriormente ser realizada análise descritiva e estatística não paramétrica. A amostragem da pesquisa tem como critério a população total residente nos municípios objetos de estudo na Microrregião de Ceres, em Goiás, Brasil.

\section{AGRONEGÓCIO - POLÍTICAS, CONSUMO E INTOXICAÇÃO}

Nos anos de 1970, o agronegócio promoveu a reestruturação do território brasileiro com "forte presença do Estado na articulação entre os agentes envolvidos nos circuitos produtivos modernos, gerando uma maior aproximação e interdependência entre agricultura e indústria" (CASTILHO, 2007, p.35). Em Goiás sua materialização ocorreu através do projeto de integração do Nordeste com a Amazônia e Planalto Central, que investiu recursos na construção de rodovias, aeroportos e redes de telecomunicações para expansão econômica.

Em 1975, através do Programa de Desenvolvimento dos Cerrados (POLOCENTRO), instituído pelo Decreto $n^{\circ}$. 75320 de 29/01/1975, ocorreram investimentos em pesquisa, assistência técnica, reflorestamento, financiamento de patrulhas motomecanizadas, bem como ampliação da infraestrutura de apoio (transportes, energia e armazenamento) e crédito rural.

O crédito rural, segundo Estevam (1997), foi o mecanismo que capitalizou as atividades agropecuárias em Goiás, subsidiando insumos, máquinas e equipamentos. O financiamento rural foi o principal responsável pela mecanização no campo e incremento na indústria de máquinas para o setor. Entre 1970 a 1985, o percentual do crédito rural em Goiás apresentou crescimento de $7 \%$ a mais do que nas demais unidades de federação brasileira. Conforme os Censos Agropecuário do Instituto Brasileiro de Geografia e Estatística (IBGE), o aumento do número de tratores em Goiás foi significativo, passando de 5.692 unidades em 1970 , para 33.548 unidades em 1985 e em 1995 chegou a 43.313 unidades (IBGE, 1970; 1985; 1996).

Nos anos 1980, a política pública do POLOCENTRO foi substituída pelo Programa de Cooperação Nipo-Brasileiro de Desenvolvimento do Cerrado (PRODECER), que teve como principal função tornar o Cerrado uma área "produtora de grãos, soja, principalmente, produtos em recessão no mercado japonês"
(INOCÊNCIO; CALAÇA, 2009, p.3)

Segundo Castilho (2007) a crise do Estado brasileiro, na década de 1980, impõe privatizações, concessões, diminuição dos subsídios e abertura comercial. A partir dos anos 1990, conforme Silveira (2016), por causa da crise econômica instaurada nos anos 1980, o Estado brasileiro atribuiu maior liberdade de mercado para agricultura. $\mathrm{O}$ autor ressalta, ainda, que em Goiás:

Estabelece-se a produção de commodities, atraindo para o seu território as grandes empresas multinacionais do setor agrícola. Disso surgiu a industrialização da agricultura e o processo de criação dos grandes conglomerados que comandam a produção (SILVEIRA, 2016, p. 122).

Conforme o IMB (2013), a agricultura do estado de Goiás é especializada na produção de commodities. Em boletim, o Instituto afirma que alimentos como arroz e feijão possuem expressão pequena diante da produção total do Estado. O documento aponta que Goiás foi um dos maiores produtores nacionais de arroz e em 2013 teve apenas $1,26 \%$ de participação na produção nacional. Fato evidenciado no cenário nacional,

Atualmente, se somadas às áreas de cultivo de arroz, feijão, trigo e mandioca, chega-se a um número próximo a 8,5 milhões de hectares, o que equivale a uma área menor do que aquela ocupada com o cultivo de cana-de-açúcar. E, se somadas às áreas destes quatro cultivos e a cana-de-açúcar, tem-se cerca de 17 milhões de hectares, ou seja, metade da área ocupada com soja (BOMBARDI, 2017, p.28).

A autora aponta, ainda, que a produção dos itens que compõem a cesta de alimentos (arroz, feijão, farinha de mandioca e trigo) tem diminuído em área cultivada e aumentado a área de soja e cana-de-açúcar (BOMBARDI, 2017), o mesmo ocorrendo no estado de Goiás.

Segundo o IMB no início da década de 2010 o estado de Goiás avançava no ranking da produção nacional, especialmente com a soja, cana-deaçúcar e milho. "No caso do milho, o último levantamento da produção agrícola apontou o Estado como o terceiro maior produtor nacional" (IMB, 2013) e no que se refere à atividade sucroenergética "o surgimento de novas usinas processadoras de cana-de-açúcar, impulsionando a produção de etanol e açúcar no Estado" (IMB, 2013), fato que posicionou Goiás em $3^{\circ}$ lugar na produção nacional de cana-de-açúcar.

Conforme dados divulgados pelo IMB, entre 
os anos de 2000 a 2013, ocorreu aumento de produção por tonelada nos cultivos de cana-deaçúcar, soja e milho em Goiás. A cana-de-açúcar aumentou $682,64 \%$; a soja $217,76 \%$ e o milho aumentou $210,05 \%$. E o aumento da área colhida da cana-de-açúcar foi de $618 \%$, da soja $197,70 \%$ e do milho, 146,45\% (IMB, 2013). Segundo a AGRODEFESA (2018), ocorreu aditamento de utilização de insumos para a produção das culturas mencionadas, entre eles, o uso de agrotóxicos.

De acordo com a AGRODEFESA (2018), 38\% dos agrotóxicos utilizados nas culturas de canade-açucar, soja e milho são extremamente tóxicos, $18 \%$ altamente tóxicos, $36 \%$ medianamente tóxicos e 7\% pouco tóxicos. Outro dado relevante disponibilizado é que são 793 agrotóxicos cadastrados para uso em Goiás e os mais utilizados são inseticidas (26,35\%), fungicidas $(21,56 \%)$ e herbicidas $(36,82 \%)$. Os demais são: reguladores de crescimento, nematicidas, espalhantes adesivos, acaricidas, feromônios, entre outros.

Segundo o Relatório Vigilância em Saúde de Populações Expostas a Agrotóxicos no Estado de Goiás (BRASIL, 2016), produzido e divulgado pelo Ministério da Saúde, ocorreu acentuado crescimento da taxa de consumo de agrotóxicos na produção agrícola em Goiás, que em 2007 foi de 25.247 .000 (kg) em uma área plantada de 3.955.025 (ha) e em 2012 aumentou para 110.497.804 (kg) de ingrediente ativo em 5.282.270 ha de área plantada (BRASIL, 2016, p.4). As informações disponibilizadas no relatório demonstram aumento de consumo de agrotóxicos entre 2007 a 2012 de $337 \%$, contrapondo-se a $33 \%$ de aumento de hectares de áreas plantadas.

Ainda segundo Relatório Nacional de Vigilância em Saúde de Populações Expostas a Agrotóxicos (BRASIL, 2016, p. 72), Goiás comercializa aproximadamente "95 milhões de quilos, o que representa $28,7 \%$ do comércio da região [Centro Oeste]". O documento ainda afirma que apesar da diminuição do comércio de agrotóxicos em Goiás em 2012, no ano seguinte

Houve aumento da incidência de intoxicações por agrotóxico, o que pode refletir o trabalho do estado na sensibilização de gestores e profissionais de saúde para melhoria dos processos de detecção e notificação dos casos de intoxicação por agrotóxicos" (BRASIL, 2016, p. 76).

Os dados disponibilizados no SINITOX (BRASIL, 2017) demonstram a oscilação e aumento do número de acidentes individuais; aumento de acidentes ocupacionais e o índice de tentativas de suicídios com uso de agrotóxicos agrícolas em Goiás. Ele expõe o aumento de casos de tentativa de suicídio em Goiás. No Brasil, segundo Ministério da Saúde, no período de 2007 a 2013, das 59.576 notificações registradas no SINAN de intoxicações por agrotóxicos, 32.369 $(54,3 \%)$ são relacionadas à tentativa de suicídio (BRASIL, 2016). O Ministério da Saúde aponta que as notificações de intoxicações por agrotóxicos em tentativas de suicídios entre 2007 a 2013 atingiram 1.435, tendo evoluído para óbito 41 casos (BRASIL, 2016).

Em Goiás, conforme Tejerina (2018), no período de 2011 a 2012, 54,52\% de intoxicação por agrotóxico de uso agrícola foram causados por tentativas de suicídio e ocorreram com mais frequência com população masculina em idade produtiva (20 a 39 anos). Outro dado levantado pela autora é que o maior número de notificação ocorreu na zona urbana.

A ingestão voluntária do agrotóxico como agente letal pode estar relacionada à facilidade de acesso e também à grande variedade existente no mercado. A facilidade de acesso a produtos nocivos à saúde pode influenciar a vítima a cometer o autoextermínio, dessa forma, a redução ao acesso pode ser uma estratégia de prevenção (TEJERINA, 2018, p.243).

Além dos casos de tentativa de suicídios, discussões sobre os malefícios provocados na saúde humana pelo uso dos agrotóxicos tem sido alvo de pesquisas. Destaca-se o relatório realizado e divulgado pela organização internacional Human Rights Watch, "Você não quer mais respirar veneno" (HRW, 2018), que apresenta estudo sobre falhas de proteção a comunidades rurais expostas aos agrotóxicos. O documento expõe que

A Human Rights Watch conduziu uma pesquisa no Brasil por diversos motivos, incluindo a quantidade significativa de agrotóxicos usados no país em relação ao consumo mundial, que muitos dos agrotóxicos usados no Brasil são altamente perigosos; e que há uma pressão política intensa para enfraquecer ainda mais o sistema regulatório do Brasil para agrotóxicos (HRW, 2018, p.34).

O documento traz relatos de pessoas atingidas por pulverização aérea, dentre eles estão os da comunidade da escola rural em Rio Verde, Goiás, que em 2013 foram atingidos por pulverização aérea de agrotóxicos. Segundo laudo técnico do documento mencionado, o agrotóxico dispensado 
pela aeronave não poderia ser usado em aviões. $\mathrm{O}$ evento causou intoxicação aguda em 42 pessoas, e, 29 ficaram internados com vômito, tonturas e dores de cabeça.

Os casos de intoxicações por agrotóxicos em Goiás, segundo Relatório da Vigilância em Saúde de Populações Expostas a Agrotóxicos no Estado de Goiás (BRASIL, 2016), entre 2007 a 2012 cresceu $87 \%$. Conforme Relatório mencionado, em 2007 a incidência de intoxicação por 100.000 habitantes foi de 4,02; em 2008, 4,24; em 2009, 6,56; em 2010, 7,38; em 2011 diminuiu para 5,54 e, em 2012, 7,52.

Conforme dados da Secretaria Estadual de Saúde de Goiás (GOIÁS, 2016), a taxa de consumo de agrotóxico no estado é de 16,96 (Kg/ha), ficando em quinto lugar no país no que se refere a risco à população em relação a agrotóxicos. Segundo o órgão, entre os anos de 2007 a 2015 foram notificadas 4.671 intoxicações por agrotóxicos em Goiás.

\section{MICRORREGIÃO DE CERES - INTOXICAÇÃO E ADOECIMENTO}

A Microrregião de Ceres (Mapa 01), localizada no centro goiano, é formada por 22 municípios, com população total de 231.239 habitantes, sendo 38.668 no espaço rural e 192.571 no espaço urbano, conforme Censo Demográfico do IBGE (2010).

Mapa 01 - Mapa da delimitação da Microrregião de Ceres e Localização dos Municípios de Barro Alto, Goianésia, Itapaci, Rialma e Uruana - Goiás, Brasil.

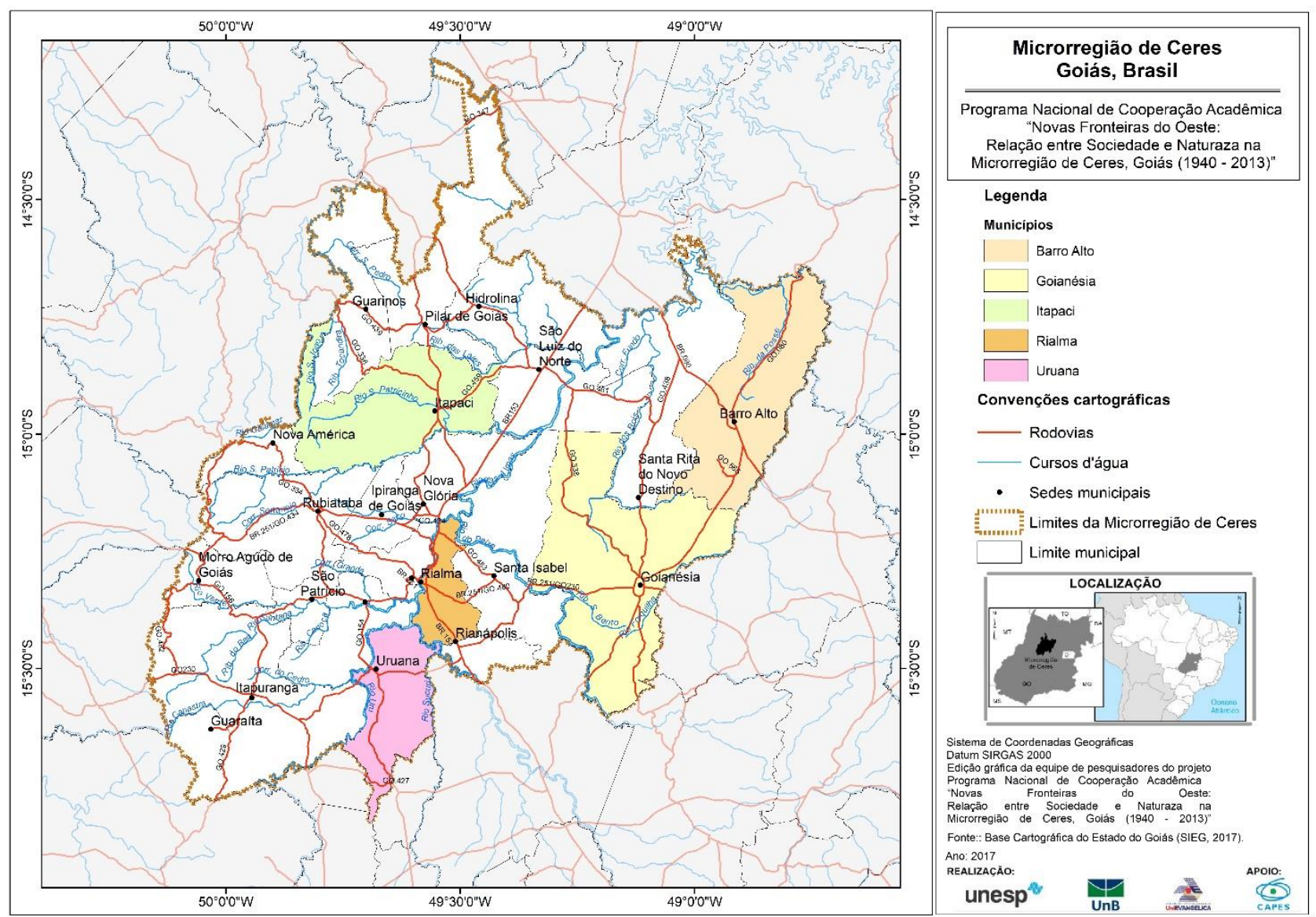

Fonte: Base Cartográfica da Sistema de Informação do Estado de Goiás (SIEG, 2017).

O processo de ocupação da Microrregião de Ceres se deu pela frente de expansão

Com a chegada dos posseiros, sem ação estatal e destacada por produções não capitalistas. A segunda fase - frente pioneira - confirmou-se no crescimento rápido da população e pela expansão das áreas cultivadas na região, com o apoio governamental de Vargas, por meio da Marcha para Oeste e da criação das Colônias Agrícolas Nacionais (CAN), com o objetivo de fixar o homem no campo por meio da pequena propriedade, voltada para a produção de bens agrícolas em escala capitalista (RODRIGUES, 2013, p.81). 
Historicamente, a ocupação da Microrregião originou-se do projeto das Colônias Agrícolas Nacionais (FREITAS; MELLO, 2014) e intensificou-se com o Programa Nacional do Álcool (PROÁLCOOL) que consolidou a dinâmica agrícola com base na agroindústria canavieira. $\mathrm{O}$ Proálcool intensificou a produção de cana-deaçúcar por meio de incentivos fiscais $\mathrm{e}$ empréstimos bancários com juros abaixo da taxa de mercado para os produtores. Tal política motivou instalação de usinas nos anos 1970 e 1980 na Microrregião de Ceres.

Entretanto,

A implantação das primeiras usinas na microrregião de Ceres data das décadas de 1960 e 1970 . Os empreendimentos pioneiros foram: a Sociedade Açucareira Monteiro de Barros, no município de Goianésia, em 1968, que foi adquirida pelo Grupo Matari, de Pernambuco, em 1989, passando a denominar-se Usina Goianésia; a usina Pite S/A, instalada em Itapuranga no ano de 1979, que funcionou até 1990, sendo reaberta em 2007 pelo Grupo Farias, de Pernambuco, tendo atualmente a designação de Vale Verde Empreendimentos Agrícolas [...] a Jalles Machado (em Goianésia), a usina do Grupo Devale (em Itapaci), e a Cooperativa Agroindustrial do município de Rubiataba (Cooper Rubi) implantadas em 1980, 1982 e 1984 (FERREIRA; DEUS,2012, p.69).

A implantação das usinas, iniciada nos anos de 1960, reorganizou o território da produção agrícola da Microrregião de Ceres. A Tabela 01 apresenta os dados da cobertura e uso do solo entre os anos de 1975 a 2013.

Tabela 01. Dados sobre a cobertura e uso do solo, Microrregião de Ceres, Goiás.

\begin{tabular}{lcccc}
\hline $\begin{array}{l}\text { Área/Ano } \\
\text { Classes }\end{array}$ & $\mathbf{1 9 7 5}$ & $\mathbf{1 9 8 5}$ & $\mathbf{1 9 9 5}$ & $\mathbf{2 0 1 3}$ \\
$\begin{array}{l}\text { Cerrado } \\
\text { denso } \\
\text { Cerrado }\end{array}$ & 54,08 & 28,66 & 26,25 & 25,02 \\
ralo & 39,90 & 33,63 & 29,03 & 27,03 \\
Drenagem & 0,89 & 0,45 & 0,52 & 0,78 \\
Pastagem & 5,06 & 35,34 & 27,28 & 24,32 \\
Cultura & 0,00 & 1,78 & 16,51 & 21,95 \\
Cultura & 0,00 & 0,00 & 0,22 & 0,47 \\
irrigada & 0,08 & 0,15 & 0,20 & 0,43 \\
\hline Cidade & 100,00 & 100,00 & 100,00 & 100,00 \\
\hline Total & & & & \\
\hline
\end{tabular}

Fonte: BARBALHO, 2018.

Conforme Barbalho (2018), ocorreu redução das áreas naturais e aumento das áreas urbanas e, especialmente, das áreas de produção agropecuária. Dados que demonstram o avanço do agronegócio. Conforme informação do Sindicato da Indústria de Fabricação de Etanol do Estado de Goiás e Sindicato da Indústria de Fabricação de Açúcar do Estado de Goiás (SIFAEG, 2018), a microrregião tem sete (7) usinas, das quais seis (6) em operação e uma (1) com operação suspensa. Os recursos naturais da área foram impactados com a expansão agrícola. A Microrregião de Ceres "teve grande parte de sua cobertura florestal devastada em função da expansão da fronteira agrícola, tanto para ocupação agrícola [e pecuária], como para a ampliação da urbanização" (DUTRA SILVA; BARBALHO; FRANCO, 2013, p. 232).

Outro dado relevante do processo de ocupação do território pelo agronegócio, conforme informações registradas no SINAN (2018), foi o número de casos de intoxicação por agrotóxicos na Microrregião de Ceres, que entre os anos de 2001 a 2013 aumentaram $1.930 \%$.

Para esta pesquisa foram selecionados cinco municípios da Microrregião de Ceres, a saber: Barro Alto, Goianésia, Itapaci, Rialma e Uruana, por produzirem em seus territórios cana-deaçúcar, milho e soja e, nos anos de 2000 a 2013, ampliarem a área de ocupação dos cultivos mencionados. E, conforme Porto e Soares (2012), são áreas que mais utilizam agrotóxico para aumento da produção e produtividade e, consequentemente, mais expõem a população a riscos. Esses municípios também têm em seus territórios concentração de pivôs centrais para irrigação, com exceção de Rialma.

Importante destacar que a produção de cana- 
de-açúcar, soja e milho nesses municípios cresceu entre os anos de 2000 a 2013, ampliando também o território de produção e diminuindo as áreas naturais do bioma Cerrado, ou ainda substituindo áreas de outras culturas.

Os municípios em estudo tiveram em seu território ampliação dos cultivos de soja, milho e cana-de-açúcar, este último com maior expansão territorial. Na Microrregião de Ceres o município de Goianésia destaca-se como maior produtor de cana-de-açúcar; Uruana de milho e Barro Alto de soja. As informações apresentam oscilações de toneladas produzida por hectare colhido, mas os municípios tiveram, de maneira geral, crescimento de área plantada e aumento de produtividade dos cultivos (IMB, 2018). Destacase o relevante aumento da produção da cana-deaçúcar em todos os cincos municípios.

Stabenow (2014) afirma que a Microrregião de Ceres expõe a contradição do sistema produtivo por apresentar, de um lado, um número reduzido de municípios que aumentaram arrecadação, melhoraram indicadores econômicos e de infraestrutura, caso visualizado entre os anos de 2007 a 2013 nos municípios de Goianésia e Barro Alto (Cf. IMB, 2018). De outro, os municípios que foram desfavorecidos

São altamente dependentes de políticas públicas, possuem atividades agropecuárias reduzidas, grande êxodo rural, estagnação de empregos formais e da economia [...] constitui $72,73 \%$ dos municípios da Microrregião de Ceres, isto é, 16 municípios do total de 22, o que corresponde, também, a 70\% da área da microrregião (STABENOW, 2014, p.67).

A autora afirma que eles tornaram-se meros fornecedores de cana-de-açúcar e sofrem com a estagnação econômica e o êxodo rural. Entre eles estão Uruana, Rialma e Itapaci (Cf. IMB, 2018).

Os dados estatísticos divulgados no sistema de informação do IMB (2018) também revelam que a produção da cana-de-açúcar, nos municípios em questão, reduziu a diversidade de produção agrícola e de propriedades rurais, inibindo outras formas de culturas agrícolas, especialmente aquelas referentes à manutenção das famílias no campo e à produção de alimentos, elegendo outra forma e função para o território.

De maneira geral, conforme dados censitários do IBGE, os municípios tiveram sua população gradativamente migrando do campo para a cidade, acompanhando uma tendência nacional de processo migratório (IBGE, 1980; 1991; 2000; 2010).

Destaca-se Goianésia como o município de maior crescimento populacional, no qual estão situadas duas usinas de grande porte que comercializam açúcar para países da América do Norte, Europa, Oriente Médio e África. Conforme Alves (2012), também a existência de outros estabelecimentos industriais, comerciais, e unidade de ensino superior exercem atração migratória inter-regional e intra-regional, além da pendular e sazonal. Segundo Ferreira (2010), em Goianésia no período da safra têm-se cerca de 4.030 trabalhadores e na entressafra 2.666, números que expõem a migração sazonal.

Os municípios possuem população urbana maior que rural, com predominância da população nas faixas etárias entre 20 a 69 anos de idade. De acordo com os Censos Demográficos (IBGE, 2000; 2010), ocorreu crescimento populacional nos municípios de Itapaci, Goianésia e Barro Alto. Já os municípios de Rialma e Uruana permaneceram, basicamente, com o mesmo número populacional.

Eles são municípios considerados com alto Índice de Desenvolvimento Humano Municipal (PNUD, 2013). Mas quando se considera isoladamente o item educação, conforme dados do IMB (2018), a maioria da população concluiu o ensino fundamental e apenas entre $5 \%$ a $8 \%$ cursaram o ensino superior.

Destaca-se, conforme Censo Demográfico (IBGE, 2010), que apesar da população concentrar-se no espaço urbano, a mesma exerce atividades no campo (pecuária, agricultura e produção de origem animal). No caso de Barro Alto são 16,26\% da população; em Goianésia, corresponde a 13,19\%; em Itapaci, 27,41\%; Rialma, $7,37 \%$ e no município de Uruana trabalham no setor agropecuário $35,52 \%$ da população economicamente ativa.

Nos municípios supracitados, a população residente torna-se vulnerável ao adoecimento por intoxicação de uso de agrotóxico em cultivos que utilizam, para aumento de produtividade, agrotóxicos extremamente tóxicos.

De maneira geral, os dados do SINAN (2018), entre os anos de 2007 a 2013, registram aumento de 295\% de intoxicação (Medicamentos, 43\%; Agrotóxico, 19\%; Raticidas, 13\%, Outros, 25\%) e aquelas referentes apenas ao agrotóxico agrícola tiveram aumento de $160 \%$.

Segundo dados do Núcleo de Vigilância Epidemiológica do Vale de São Patrício (NVEVSP, 2018) registram-se herbicidas (Glifosato, Volcane, Integrity e Tordon) e inseticidas (Barrage, Furadan, Lannate, Confidor, Baygon, Diazitop) como os principais praguicidas responsáveis por intoxicação. Conforme a Secretaria de Saúde de Goiás (GOIÁS,2016), os municípios de Goianésia, Uruana, Rialma e Itapaci registram entre 2 a 20 intoxicações por agrotóxicos notificadas por ano, 
com exceção do município de Barro Alto que registra mais de 20 intoxicações notificadas.

Os municípios em estudo também registraram aumento de casos de óbito por neoplasia, com destaque para o município de Goianésia que entre 2000 a 2013 registrou aumento correspondente a 156,5\%. Rialma em 2000 registrou aumento de $171 \%$ de casos. Uruana, de $180 \%$ de óbitos por neoplasia. Em Itapaci e Barro Alto registrou-se aumento de 100\% (SIM, 2018; SINAN, 2018).

Os municípios, conforme SIM (2018), tiveram aumento anual dos casos de óbitos por neoplasia, evidenciando um número de óbito maior no sexo masculino, com baixa escolaridade, pardos e negros (SIM, 2018). Conforme dados do SINAN (2018), os tipos de neoplasia que levaram a óbito mais recorrentes foram: neoplasia maligna dos olhos, encéfalos e outros partes do sistema nervoso central; do tecido linfático hematopoético e correlatos; neoplasia maligna do aparelho respiratório e órgãos intratorácicos, neoplasia maligna dos órgãos genitais masculinos e neoplasia maligna dos órgãos digestivos. Os três últimos com maior incidência nos municípios mencionados.

Nas mulheres, os casos de óbitos por neoplasia maligna têm maior incidência nas com idades de 40 a 49 e 50 a 59 anos, de cor parda ou negra. Conforme informação disponibilizada no SIM as três principais são neoplasia maligna de órgão digestivo; respiratória e órgão intratorácicos e neoplasia maligna de órgãos genitais femininos (SIM, 2018).

Outros dados relevantes dizem respeito aos registros no SINAN (2018) do aumento de casos de malformação congênita, ou seja, defeito na constituição de algum órgão ou conjunto de órgãos que determine uma anomalia morfológica estrutural presente no nascimento devido à causa genética, ambiental ou mista. Entre os nascidos vivos do período de 2000 a 2013, as malformações congênitas que aparecem em maior quantidade são: a) do sistema nervoso; b) fenda labial e palatina; c) dos pés e d) deformações congênitas do aparelho osteomuscular mas, sendo as duas últimas mencionados em maior número. Segundo registro do SINAN (2018), no município de Barro Alto registra-se aumento de 7,60\% nos casos de malformações congênitas; Goianésia, 5,96\%; Itapaci, 1,93\%; Rialma, 5,39\% e Uruana, 5,33\%, entre os anos de 2000 a 2013.

\section{CONSIDERAÇÕES FINAIS}

O estado de Goiás consolida-se hoje como um dos principais produtores de grãos e de cana-deaçúcar do país e apresenta empreendimentos agroindustriais em funcionamento em suas diversas microrregiões. A Microrregião de Ceres, desde a década de 1960, teve sua economia direcionada para o aumento de produção agrícola, especialmente a canavieira com a instalação das primeiras usinas.

A configuração territorial da Microrregião de Ceres foi sendo alterada em razão das demandas econômicas e suas consequências, materializadas na expansão urbana desigual, na perda de biodiversidade, nas desigualdades sociais e, como evidenciam os dados, o adoecimento da população por neoplasias e malformações congênitas tem ocorrido de forma concomitante ao aumento do uso do agrotóxico, especialmente para a produtividade agrícola de cana-de-açúcar, milho e soja.

Refletir sobre a interface entre agronegócio/agrotóxico/adoecimento possibilita propor uma agenda de discussão interdisciplinar e interinstitucional que envolva o uso do território goiano e o adoecimento da população. O adoecimento da população está vinculado às transformações e formas do uso do território, pois, de forma direta ou indireta, é possível compreender as relações entre os processos de produção do território e processo saúde-doença humana na ocorrência de diferentes agravos, dentre eles as intoxicações agudas ou graves.

\section{AGRADECIMENTOS}

O presente trabalho foi realizado com apoio da Coordenação de Aperfeiçoamento de Pessoal de Nível Superior - Brasil (CAPES) - (PROCAD CAPES - processo n ${ }^{\circ}$ 2980/2014).

\section{REFERÊNCIAS}

ABREU, P.H.B.de; ALONZO, H. G. A. O agricultor familiar e o uso (in) seguro de agrotóxicos no município de Lavras/MG. Revista Brasileira de Saúde Ocupacional, v. $41, \quad$ p.1-12, 2016. https://doi.org/10.1590/2317-6369000130015

ACQUAVELLA, J. et al. Cancer among farmers: a meta-analysis. Annals of Epidemiology, v. 8, p. 64-74, 1998. https://doi.org/10.1016/S1047-2797(97)001208

AGRODEFESA. Agência Goiana de Defesa Agropecuária. Agrotóxicos. 2018. Disponível 
em:

<http://www.agrodefesa.go.gov.br/post/ver/186 586/agrotoxicos>. Acesso em: 03 de Fevereiro de 2018.

ALAVANJA, M. C. et al. Use of Agricultural Pesticides and Prostate Cancer Risk in the Agricultural Health Study Cohort. American Journal of Epidemiology, v. 157, p. 800-814, 2003. https://doi.org/10.1093/aje/kwg040

ALAVANJA, M. C. et al. Pesticides and lung cancer risk in the agricultural health study cohort. American Journal of Epidemiology, v. $160, \quad$ p. $876-885, \quad 2004$ https://doi.org/10.1093/aje/kwh290

ALBUQUERQUE, P.C. C. de et al. Sistemas de informação em saúde e as intoxicações por agrotóxicos em Pernambuco. Revista Brasileira deEpidemiologia, v. 18, p. 666678, 2015. https://doi.org/10.1590/19805497201500030012

ALVES, G. L. F. Expansão canavieira e seus efeitos na violência em Goianésia. Dissertação (Mestrado em Agronegócio) Goiânia: UFG, 2012.

BARBALHO, M. G. Relatório de Pósdoutoramento. Brasília: UnB, 2018, 65p.

BOMBARDI, L. M. Atlas: Geografia do Uso de Agrotóxicos no Brasil e na Europa.2017. Disponível

em:

<https://www.larissabombardi.blog.br/atlas20 17> Acesso em: 20 de Novembro de 2017.

BRASIL Ministério da Saúde. Protocolo de Atenção à Saúde dos Trabalhadores Expostos a agrotóxicos, 2013. Disponível em:

<http://bvsms.saude.gov.br/bvs/publicacoes/pr otocolo_atencao_saude_trab_exp_agrotoxicos. pdf $>$ Acesso em: 09 de Dezembro de 2017.

BRASIL. Ministério da Saúde. Relatório Vigilância em Saúde de Populações Expostas a Agrotóxicos no Estado de Goiás. 2016. Disponível em: <http://portalarquivos2.saude.gov.br/images/p df/2015/julho/08/Relat--rio-Goi--s.pdf $>$. Acesso em: 01 de Janeiro de 2018.

BRASIL. Ministério da Saúde Sistema Nacional de Informações Tóxico-Farmacológicas Casos registrados de intoxicação humana e envenenamento: região Centro Oeste. 2017. Disponível em: <http://www.fiocruz.br/sinitox.> Acesso em: 20 de Junho 2017

CARNEIRO, F. F. et al. Dossiê: Um alerta sobre os impactos dos agrotóxicos na saúde. Rio de Janeiro: EPSJV; São Paulo: Expressão Popular, 2015.

CASTILHO, D. A dinâmica socioespacial de Ceres e Rialma-GO no âmbito da modernização de Goiás: território em movimento, paisagens em transição. Tese (Doutorado em Geografia) - Goiânia: UFG. 2007.

CORCINO, C. O. et al. Avaliação do efeito do uso de agrotóxicos sobre a saúde de trabalhadores rurais da fruticultura irrigada. Ciência Saúde Coletiva, v. 24, p. 38-51, 2019. https://doi.org/10.1590/141381232018248.14422017

DAYRELL, E. G. Colônia Agrícola Nacional de Goiás: análise de uma política de colonização. Tese (Doutorado em História) Goiânia: UFG, 1974.

DOULL, J.; LEVIEN, R.S. Global estimates of acute pesticide morbidity and mortality. Reviews of Environmental Contamination and Toxicology, v. 129, p.29-44, 1993. https://doi.org/10.1007/978-14684-7106-9_3

DUTRA SILVA, S.D.; BARBALHO, M.G.; FRANCO, J.L. A Expansão sucroalcooleira e a devastação ambiental nas matas de São Patrício, Microrregião de Ceres, Goiás. História, histórias, v. 01, p. 230-247, 2013.https://doi.org/10.26512/hh.v1i2.10735

EATON, D.L.et al Review ofthe toxicology of chlorpyrifos with an emphasison human exposure and neurodevelopment.critical Reviews in Toxicology, v.2, p.1-125, 2008. https://doi.org/10.1080/10408440802272158

ESTEVAM, L. O tempo da transformação : estrutura e dinâmica na formação econômica de Goiás. 1997. 245 f. Tese (Doutorado em Economia) - Campinas: UNICAMP. 1997.

FREITAS, W. A.; de MELLO, M. de. A colônia agrícola nacional de Goiás e a redefinição nos usos do território. Sociedade \& Natureza, v. 26, p. 471-482, 2014. https://doi.org/10.1590/1982-451320140306.

FERREIRA, L. C. G. A evolução do setor sucroalcooleiro na microrregião Ceres (GO): dinâmica espacial e impactos socioeconômicos. Dissertação (Mestrado em Geografia) - Goiânia: UFG, 2010.

FERREIRA, L. C. G.; DEUS, J. B. de. O uso do território e as redes na microrregião de Ceres (GO): o caso das agroindústrias sucroalcooleiras. Boletim Goiano de Geografia, v. 30, p.67-80, 2012. https://doi.org/10.5216/bgg.v30i2.13795

GOIÁS. Secretaria de Saúde do Estado de Goiás. Uso de agrotóxicos na RS Central. Notificação de intoxicações por agrotóxicos em Goiás. 2016. Disponível em: <http://www.sgc.goias.gov.br/upload/arquivos/ 2016-06/uso-de-agrotoxicos-na-rscentral.pdf>. Acesso em: 02 de Março de 2018. 
HRW - Human Rights Watch. "Você não quer mais respirar veneno" as falhas do Brasil na proteção da comunidades rurais expostas à dispersão de agrotóxicos, 2018. Disponível em: <https://www.hrw.org/pt/report/2018/07/20/32 0417> Acesso em: 28 de Julho de 2018.

IBGE - Instituto Brasileira de Geografia e Estatística. Censo Agropecuário. 1970. Disponível em: <https://biblioteca.ibge.gov.br/visualizacao/per iodicos/45/ca_1970_v3_t23_go.pdf $>$ Acesso em: 03 de Outubro de 2018.

. Censo Agropecuário. 1985. Disponível em:

$<$ https://biblioteca.ibge.gov.br/visualizacao/per iodicos/47/ca_1985_n27_go.pdf> Acesso em: 03 de Outubro de 2018.

Censo Agropecuário.1996. Disponível em:<https://biblioteca.ibge.gov.br/visualizacao /periodicos/48/agro_1995_1996_n25_go.pdf>

Acesso em: 03 de Outubro de 2018.

Censo Demográfico. 1980. Disponível em:

$<$ https://biblioteca.ibge.gov.br/visualizacao/per iodicos/72/cd_1980_v1_t4_n25_go.pdf> Acesso em: 03 de Outubro de 2018..

Censo Demográfico. 1991. Disponível em:

<https://biblioteca.ibge.gov.br/visualizacao/per iodicos/82/cd_1991_n27_caracteristicas_popul acao_domicilios_go.pdf > Acesso em: 19 de Outubro de 2018. em:

Censo Demográfico. 2000. Disponível

<https://biblioteca.ibge.gov.br/visualizacao/per iodicos/83/cd_2000_caracteristicas_populacao_ amostra.pdf $>$ Acesso em: 19 de Outubro de 2018. em:

Censo Demográfico 2010. Disponível

<https://censo2010.ibge.gov.br/resultados.htm l> Acesso em: 19 de Outubro de 2018.

IMB - Instituto Mauro Borges. Dados sobre Goiás. 2018. Disponível em: <http://www.imb.go.gov.br/index.php?option= com_content\&view=category\&layout=blog\&id $=19 \&$ Itemid $=151>$. Acesso em: 18 de Janeiro de 2018.

Conjuntura Econômica Goiana. Boletim

Trimestral SEGPLAN, n. 24, p. 1-102, 2013. Disponível

em:

<http://wwwold.imb.go.gov.br/down/conjuntur a24.pdf>. Acesso em: 20 de Março de 2018.

INOCÊECIO, M. E.; CALAÇA, M. Cerrado: fronteira da produção capitalista do século XX. In: ENCONTRO NACIONAL DE GEOGRAFIA AGRARIA, 19.,2009, São Paulo, Anais [...] São Paulo: USP, 2009, p. 1- 16.
INOCÊNCIO, M. E. O PROCEDER: as tramas do poder na territorialização do capital no Cerrado: o PRODECER. Tese (Doutorado em Geografia) - Goiânia: UFG. 2010.

JOBIM, P. F. C. et al. Existe uma associação entre mortalidade por câncer e uso de agrotóxicos? Uma contribuição ao debate. Ciência Saúde Coletiva, v. 15, p. 277-288, 2010. https://doi.org/10.1590/S141381232010000100033

LEVINE, R. S.; DOULL, J. Global estimates of acute pesticide morbidity and mortality. Ver. Environmental Contamination and Toxicology, v. 129, p. 29-50, 1992. https://doi.org/10.1007/978-1-4684-7106-9_3

MATOS, P. F. de. Agronegócio no sudeste goiano e as disputas pelo uso do território. Acta Geográfica, v. 3, p.153-165, 2013. https://doi.org/10.5654/actageo2013.0003.0008

As tramas do agronegócio nas"terras" do Sudeste Goiano. Tese (Doutorado em Geografia) - Uberlândia: UFU. 2011.

NVEVSP - Núcleo de Vigilância Epidemiológica do Vale de São Patrício. 2018. Disponível em: < https:/www.saude.go.gov.br/vigilancia-emsaude/vigilancia-epidemiologica> Acesso em: 06 de Setembro de 2018.

PNUD - Programa das Nações Unidas para o Desenvolvimento. Atlas do Desenvolvimento Humano. 2013. Disponível em: <http://atlasbrasil.org.br/2013/> Acesso em: 10 de Agosto de 2017.

PORTO, M. F.; SOARES, W. L. Modelo de desenvolvimento, agrotóxicos e saúde: um panorama da realidade agrícola brasileira e propostas para uma agenda de pesquisa inovadora. Revista Brasileira Saúde Ocupacional, v.37, p.17-31, 2012. https://doi.org/10.1590/S030376572012000100004

RODRIGUES, D. M. T. Sustentabilidade do setor sucroalcooleiro na Microrregião de Ceres - GO, Tese (Doutorado em Ciências Ambientais). Goiânia: UFG. 2013.

SIEG. Sistema Estadual de Geoinformação. Base Cartográfica do Sistema de Informação do Estado de Goiás. 2017. Disponível em: <http://www.sieg.go.gov.br/siegmapas/mapa.p hp>. Acesso em: 20 de Dezembro de 2017.

SIFAEG. Sindicato da Indústria de Fabricação de Etanol do Estado de Goiás. 2018. Cana de Açúcar. Disponível em: $<$ http://www.sifaeg.com.br/cana-deacucar/>Acesso em: 20 de Outubro de 2018.

SILVA, J. M. da et al . Agrotóxico e trabalho: uma combinação perigosa para a saúde do trabalhador rural.Ciência e Saúde Coletiva, 
v. $\quad 10$, p. $\quad$ 891-903, 2005 . http://dx.doi.org/10.1590/S1413-

81232005000400013

SILVEIRA, M. R. da. A dinâmica do agronegócio no estado de Goiás e a centralidade do município de Rio Verde. Tese (Doutorado em Geografia) -Brasília: UnB. 2016.

SIM: Sistema de Informação sobre Mortalidade. Brasil, 2018. Disponível em: <http://tabnet.datasus.gov.br/cgi/deftohtm.exe ?sim/cnv/obt10uf.def>. Acesso em: 18 de Outubro 2018

SINAN: Sistema de Informação de Agravos de Notificação. Brasil, 2018. Disponível em: <http://www2.datasus.gov.br/DATASUS/index .php? area $=0203 \& i d=29878153>$ Acesso em: 18 de Outubro 2018.

STABENOW, P. Levantamento de indicadores e as dimensões de sustentabilidade: a expansão do setor agropecuário e sua relação com a saúde pública na Microrregião de Ceres (município de Itapuranga) - GO. Mestrado (Dissertação em Ecologia) - Goiânia: PUC - GO. 2014.

STOPPELLI, I. M. de B. S. Agricultura, ambiente e saúde: uma abordagem sobre 0 risco de contato com os agrotóxicos a partir de um registro hospitalar de referência regional. Tese (Doutorado em Saúde) - São Paulo: USP. 2005.

TEJERINA, G. R. de L. Intoxicações e óbitos por agrotóxicos no Estado de Goiás, Brasil e Inovações Legislativas Caderno IberoAmericanos de Direito Sanitário, v. 7, p. 01-21, 2018.

https://doi.org/10.17566/ciads.v7i1.471 